\title{
INTEGRATING MAKERSPACES INTO ENGINEERING DESIGN
}

\author{
Mohamed Galaleldin, Justine Boudreau and Hanan Anis \\ University of Ottawa - Faculty of Engineering, 161 Louis Pasteur, Ottawa, Canada, K1N 6N5 \\ mgala028@uottawa.ca, jboud030@uottawa.ca, hanis@uottawa.ca
}

\begin{abstract}
Makerspaces are informal sites in which people with similar interests can collaboratively build creative projects by using emerging technologies. In recent years, makerspaces have been created on most campuses and often linked to STEM learning practices. However, integrating makerspaces in engineering curriculum is often not done formally. In this paper, we discuss how the University of Ottawa integrated its makerspace into its cornerstone design curriculum and its design challenges. Cornerstone engineering design includes first- and second-year courses where students learn and apply design knowledge while working in teams. Each team is expected to develop three prototypes during the semester and solve a design problem for a client. Maker components are integrated in the labs, where many makerspace technologies, such as $3 D$ printing and laser cutting, are taught and used in the development of the prototypes. In addition, the makerspace offers a yearly multidisciplinary client-based design challenge that is open to all students. This paper explores the integration of maker ideology and technology in curricular and extracurricular design activities. The paper outlines the connection between making and engineering design, the maker capacity for inclusion and sharing, the role of making activities in developing the identity of future engineers and the integration of course work into the makerspace.
\end{abstract}

Keywords: Community of Practice, Rapid Prototyping Facilities, Makerspace, Engineering Identity, Engineering Design.

\section{INTRODUCTION}

In the past decade, there have been calls to increase students' exposure to sciences, technology, engineering and math (STEM) in K-12 curriculum and to hands-on and design experiences in college-level engineering curriculum [1, p.152], [2].

The maker movement has presented a great opportunity to respond to these calls by providing educational institutions with access to digital, physical and logic tools, by building a community that encourages tinkering and making, and by encouraging students to develop a maker mindset [3], which is characterized as curious, playful, optimistic, persistent, resourceful, risktaking and having a willingness to take responsibility, take risks and share information [4].

Makerspaces, which represent the physical space for cultivating maker communities, help create communities of practice in formal education environments. Makerspaces represent a hybrid model of learning that incorporates learning and creating in participatory cultures with pedagogical structures found in more formal studio-based settings [5], yet learning opportunities in makerspaces are regarded as unique from both participatory cultures and formal studio-based settings in the marked diversity of learning arrangements they offer. Participants enhance their learning experiences by sharing their creations within the makerspace community through events, social media and websites. This heightens their skills and knowledge of tools, allowing them to be creative and access new communities and learning opportunities [5].

The integration of making activities into engineering curriculum exposes students to design activities and experiential learning technologies [6]. Making activities are also valuable learning experiences that align with engineering schools' aspired learning outcomes because they engage students in learning by allowing them to create physical or digital objects through access to sophisticated tools that engage them in new forms of thinking, support experimentation and advocate a growth mindset that encourages persistence, challenge-seeking and learning [6].

Although many universities have opened makerspaces on their campuses, the integration of making activities within the engineering curriculum remains a challenge. In this paper, we show how the Faculty of Engineering at the University of Ottawa has been working to integrate making activities into its curriculum. This paper also addresses the following questions:

RQ1: How does belonging to a maker community shape students' engineering identity? 
RQ2: How is competency defined in a makers community of practice?

\section{MAKERSPACE INTEGRATION}

The University of Ottawa's Centre for Entrepreneurship and Engineering Design (CEED) is composed of seven facilities. They include a makerspace with digital prototyping tools, a machine shop with traditional prototyping tools and training centers for all types of equipment. Undergraduate students of all years and graduate students are able to use the spaces to gain knowledge and skills, as the spaces are open to all students in the university during the week. The makerspace is also open to the outside community on Sundays. Personal and school projects can be worked on by all users for free. These spaces have evolved and expanded over the last few years. The makerspace was launched in 2014 with a few pieces of technology, like some 3D printers, Handibots (hand-held CNC routers), a few hand tools and computers. It is open eight hours a day and is staffed with people who started as undergraduate students but are now graduate students and recent alumni. The makerspace doubled in size in 2015, and the Manufacturing Training Centre (MTC) and the Makerlab (a makerspace training and design course lab space) launched in 2016. All but one CEED space then moved into a new STEM building in 2018, where the makerspace, Makerlab and most of the facilities at least doubled in size.

There are two cornerstone engineering design courses at the University of Ottawa, a first- and a second-year course. They are both client-centered and prototypebased. The student groups meet with the client three times to determine the client's needs and receive feedback based on their conceptual drawings and prototypes. Teams are expected to generate three prototypes during each term, and the final prototypes are judged by external judges on Design Day.

All CEED facilities are leveraged in these courses, where the students learn about the different equipment in their labs. The uOttawa projects are mechatronic, civil or software in nature most of the time. They can include mechanical, electronic, hardware and software parts. To accomplish this, 3D printers, laser cutters, microcontrollers, mills, drill presses, etc. can be used. Based on the project being done, students will use one or both of the main facilities (the makerspace or the machine shop) to build their prototypes.

In the labs for the first-year course, the students are taught Microsoft (Word, Excel and Project), Arduino programming, sheet metal work, Solidworks, Matlab, soldering and laser cutting. They also have an extra lab on a subject that is relevant to their project.

The second-year course labs include sheet metal work, milling, lathe, Arduino programming, 3D printing, soldering, printed circuit board design and mobile application.

The design courses take advantage of these rapid prototyping spaces to build curriculum around them. None of the projects built by the teams would be possible without the equipment and expertise available. Makerspaces are a perfect place for a design course because students can apply their theoretical knowledge in hands-on projects. Makerspace technology allows them to do that in a fast and inexpensive way. It permits customization and the freedom to develop all kinds of different designs.

The makerspace also hosts an annual design challenge open to all students to participate by submitting a prototype for a $\$ 1000$ prize. The 2019 challenge, the fifth iteration of the challenge, was a virtual reality (VR) project in the medical field. Past challenges have included a prosthetic hand, a pulse oximeter and an interactive art installation. The challenges give students opportunities to engage in an extracurricular hands-on project using engineering skills and applying them to a meaningful problem.

Through exposure to the makerspace and other design spaces, students can collaborate with like-minded peers and participate in a community where they will find lifelong learning opportunities. The open spaces, with little restrictions on the use of equipment and participants, allow the students to be included in the community of practice and learn from it if they wish.

\section{BACKGROUND}

Identity is a concept that figuratively combines the intimate or personal world with the collective space of cultural forms and social relationships [7]. Identity has also been defined as the self-constructed categories of membership that a person claims to belong to, along with the personal meanings and experiences they attach to each category [8]. This definition of identity conceptualizes social and personal identities as interrelated, since 
personal identity is defined by group membership and social categories are infused with personal meaning.

Researchers have attributed many motivations and functions to social identities, such as the enhancement of self-esteem [9], finding one's place in a universe of possibilities, the need for self-knowledge, meaning, balance, consistency, power and control [10], and uncertainty reduction [11], [12]. The motivation behind the development of social identity may also vary substantially per category of membership [13].

There are four perspectives to how identity is formed: the forces of nature, the institutional positions we assume in life, our individual traits — individuality — and how others recognize us through them, and the distinctive experiences and practices that we have as part of an affinity group [14].

This study is concerned with the impact of being a maker and belonging to an affinity group of makers - a makers community of practice — on students' sense of engineering identity. Communities of practice are "groups of people who share a passion about a topic, interact on an ongoing basis to deepen their knowledge and expertise, share information, insight and advice, and help each other to solve problems" [15]. In the context of learning, a community of practice is wherever the learner develops the values, norms, relationships and identities appropriate to the community. It is through participation that new community members understand and engage with the tools, language and practices of the community, until they themselves become old-timers [16]. For learners to become full members of a community of practice, they must interact with its members and be involved in the community's activities and language [17]. Newcomers and old-timers depend on one another, as newcomers need to learn to become old-timers, and old-timers need to carry on the practice. At the same time, the success of both new and old members depends on the eventual replacement of old-timers by newcomers who have become old-timers themselves. This introduces tensions in the learning processes, and the success and future of the community of practice depends on finding resolutions to underlying conflicts created by the tensions [18].

To study students' engineering identity and sense of belonging to engineering and how being a member of a makers community of practice has affected their learning and development of an engineering identity, we used the modes of identification in a landscape of practice used by Etienne and Beverly Wenger-Trayner [19] to describe how individuals build their identities in a landscape of practice. The three modes of identification are:

- Engagement: engaging in practice, doing things, working on issues, talking, using and producing artifacts, debating, and reflecting together
- Imagination: constructing an image of the landscape that helps us understand who we are in it, which helps the learner to create relations of identifications that are as significant as those derived from participation

- Alignment: making sure that activities are coordinated, that laws are followed or that intentions are implemented

\section{METHODS}

To answer the study's questions, we used semistructured interviews with seven engineering students who frequent the uOttawa makerspace at the University of Ottawa and are mentors in the makers community of practice $(\mathrm{CoP})$ that has formed in the makerspace. Students were invited to participate in the study via email sent by the makerspace coordinator. Participation in the study was voluntary. Research ethics approval was granted by the university's research ethics board to conduct the interviews. We used Dedoose (https://www.dedoose.com/) as our qualitative analysis tool and grounded theory to analyze interview transcripts and identify patterns and themes between participants.

In this study, students were asked about their perception of being an engineer and a maker, challenges they have faced as engineers or makers, the types of members of this makers CoP, skills they have learned in the makerspace, how competency is defined in the makerspace, and how participating in this makers CoP has affected their experience at the Faculty of Engineering. Interviews were then transcribed and coded using grounded theory to identify themes and patterns.

\section{RESULTS}

Students were asked if they considered themselves to be a member of the makers $\mathrm{CoP}$, what their frequency of participation in the CoP was, what it means for them to be engineers or makers, and if they considered themselves to be makers. We also asked students about their general interests, hoping to understand if there is a common theme that unifies students who participate in a makers CoP. Another factor we looked at was social anxiety: we asked students how social they considered themselves to be, and how comfortable they are in new situations and environments. 
Table 1: Study Sample.

\begin{tabular}{|c|c|c|c|}
\hline Pseudonym & $\begin{array}{l}\text { Engineering } \\
\text { Discipline }\end{array}$ & $\begin{array}{l}\text { Year of } \\
\text { Study }\end{array}$ & Gender \\
\hline $\mathrm{Ju}$ & $\begin{array}{l}\text { Mechanical } \\
\text { Engineering }\end{array}$ & Graduate & Female \\
\hline $\mathrm{Da}$ & $\begin{array}{l}\text { Electrical } \\
\text { Engineering }\end{array}$ & $\begin{array}{l}\text { Fourth } \\
\text { Year }\end{array}$ & Male \\
\hline Ma & $\begin{array}{l}\text { Electrical } \\
\text { Engineering }\end{array}$ & $\begin{array}{l}\text { Second } \\
\text { Year }\end{array}$ & Female \\
\hline $\mathrm{Mu}$ & $\begin{array}{l}\text { Computer } \\
\text { Engineering }\end{array}$ & $\begin{array}{l}\text { Fourth } \\
\text { Year }\end{array}$ & Male \\
\hline $\mathrm{Ki}$ & $\begin{array}{l}\text { Computer } \\
\text { Engineering }\end{array}$ & First year & Female \\
\hline $\mathrm{Bi}$ & $\begin{array}{l}\text { Computer } \\
\text { Engineering }\end{array}$ & $\begin{array}{l}\text { Second } \\
\text { year }\end{array}$ & Male \\
\hline $\mathrm{Za}$ & $\begin{array}{l}\text { Civil } \\
\text { Engineering }\end{array}$ & $\begin{array}{l}\text { Fourth } \\
\text { year }\end{array}$ & Female \\
\hline
\end{tabular}

To understand how being a member in this makers CoP affects engineering identity, we asked students about images they hold for themselves as makers and engineers and activities done within the makers CoP that they qualified as engineering practice. We also asked if being part of the makers $\mathrm{CoP}$ had helped them gain a better understanding of the responsibilities of being a professional engineer.

We also aimed to gain a better understanding of the students' satisfaction with their experience at the Faculty of Engineering and the challenges they faced as engineers and makers.

A clear common theme was that none of the participants in the study had a clear picture of engineering practice before applying to the Faculty of Engineering. Their reasons for joining the faculty included interest and high academic achievement in sciences and mathematics courses in high school, family influence or expectations, and interest in making a change in society. Students also expected academic work in school to be hard; moreover, they expected a big workload.

"Going into grade 12, you know, you have to apply to university, and I had no idea what I wanted to do but I knew I liked math and science and stuff, but I had no idea. It was really one of my classmates who like, 'Oh, you should go into engineering,' and so I kind of looked into it a little bit and then I was like, 'Oh, OK, this is a good idea,' and I just applied." — a female graduate mechanical engineering student

"I come from a rural high school, and the technology there was not great. Our computer class was mostly Excel and Word, which is why I was never introduced to coding and never knew that I loved it that much because I never had a chance to experience that in high school." - a first-year computer engineering student

\subsection{Makers CoP}

The majority of the users of the space are engineering students, since the makerspace is situated at the Faculty of Engineering, and especially from the mechanical, electrical, and computer sciences and software engineering departments. There are, however, also members of the community of makers from the faculties of science, arts, social sciences and education. Projects done in the makerspace vary based on the day of the week and the semester progression; from the beginning to the middle of the semester, projects in the makerspace are mostly personal extracurricular projects, while from the middle to the end of the semester, projects that are part of the course work of engineering design courses tend to take priority in the makerspace. Sundays are reserved as a community day, where members of the public gain access to the makerspace's resources; people of all ages and backgrounds come to the makerspace to use tools and equipment in the space and interact with the students in the makers CoP. Most of the adult participants on community day are from academic backgrounds other than engineering.

"It's actually very diverse. It's very interesting. So it's mainly engineering students from the faculty; however, we do have students from social science or health science or science who just want personal projects. So I would say in the first month of the semester, it's people who come in for personal projects - so either something they are interested in, a little ... key chain, things like that. And as we progress through the semester, it does get dominated by people who are doing class projects - so capstone projects, design projects, product development projects.... These people tend to come in because they have deadlines and they tend to be the ones who are using the space, I would say, at the time. ... Reading week, not when people are doing these projects, I would say it's 5050: half personal and half school projects." - a first-year female computer engineering student 
Although members of the community come from different backgrounds and have different interests, they all share one commonality, which is interest in and passion for making and creating their own designs. Students learned from their peers from other engineering disciplines, from students from other faculties and from those they meet on community day.

"The majority of the people have the same maker mentality. Once in a while, you meet people who come through courses who don't have this mentality, and ... it takes a little push to see the light and they realize 'look we made something, and we liked it, and somebody liked it.' I believe we almost converted that person to be a maker." - a third-year male computer engineering student

Entry to the makers CoP is facilitated through either a course that offers training in the makerspace, working with summer camps on campus, working in the Maker Mobile program (a makerspace van that travels to school, libraries and community centers in the region), participating in workshops offered in the makerspace, or a friend who in turn introduces them to the members of the makers communities of practice. Also, state-of-the-art technologies such as the Oculus rift, 3D printing and laser cutting have contributed to attracting engineering students to the makerspace for both personal and curricular projects. Another major factor in introducing students to the makers $\mathrm{CoP}$ is the community that has formed in the makerspace of diverse young talented individuals who share a common mindset of curiosity, interest in making, playing, tinkering, design and sharing their knowledge.

"In the beginning, I thought, 'it's the equipment - I come in and the equipment is exciting.' But the more I knew the people, I think it's them because we have the same mindset. And then now there are days when I am done, I just come chat with the people and see what they have done, and if there is anything new, and if anybody needs help here and there." - a fourth-year male computer engineering student

Students expressed that these resources empower them to realize their designs and help them find projects to do. Although free access to technology was one of the main reasons for students' membership in this community of practice, they put more emphasis on the community as the main reason that keeps them coming back.

The interaction between students from different disciplines helps students to gain knowledge and learn skills pertaining to different engineering disciplines, such as CAD software, programming languages, and the use of rapid prototyping equipment and niche technologies such as virtual reality. Students have also improved their soft skills such as social interaction skills and the ability to better explain their ideas to their peers and non-engineers. Moreover, students also noted that they gained different skills from students from other faculties who introduced them to a different perspective to design.

"I've learnt a little bit of SolidWorks, circuiting from people who are in electrical engineering (they have, like, a GNG1103 course), and it's just helping people with projects, and often it feels like small things, but then eventually you realize that actually I have learnt a fair amount of skills helping people with their different courses." - a first-year female computer engineering student

"I have learned how to solder from one community member who is a high school teacher. I learned about Pokemon from the six-year-old who is, like, sprinting. And I have learned a lot from asking people about their life experiences - I have learned a lot from that. Because people tend to tell me, I don't know, they are like, 'why are you making this?' and then they are like, 'I want to make this,' and that's cool, obviously - you learn from everybody's experiences. I have learned from their experiences and from their technical knowledge as well." — a first-year female engineering student

"We had a few weeks ago someone from political science I believe, and he was doing a personal project because he was super interested in technology but also loved his degree, and he came in asking for a certain type of motor. So it was super interesting to learn from him. And obviously when people come in, you also talk with them, so he was telling me about how he is in political science, but he has also done an internship in technology because he loves it and has experience now with the makerspace. I just thought it's super interesting about someone who is using it literally only for personal projects, for projects he is never going to be graded on. It was incredible. ... What I like about the makerspace is that there are a lot of different students in different degrees who want different things out of the makerspace. I think that's really cool because we get to learn from each other." - a fourth-year female civil engineering student

\subsection{Definition of Competency in the Makerspace}

In the literature about the maker movement, there has been a debate about what counts as making and who is a maker. Although there are several definitions of making activities and makers, these definitions might not 
necessarily reflect what the members of this movement know about these definitions, whether they buy into these definitions and whether they embody them in daily practice [20]. We tried to understand what makerengineering students defined as making and how they defined competency within their community.

Students defined a maker as someone who is passionate about creating things and who shares their knowledge and the artifacts they create with others. One student emphasized that a maker is someone who uses technology to create new things, while another stressed that a maker is "a maker of the world, not a user." All the students agreed that being an engineer inherently means you are a maker.

"A maker to me is just anyone who tinkers and makes things, anyone who puts creative thought into making something, and not even a useful thing, as long as you made something, not even solving a problem like engineering making, just putting things together — that's a maker." — a first-year male software engineering student

As newcomers to the community participate in activities and work to gain the knowledge and language to become competent makers, they have to gain various skills through their learning journey. For makers to be seen as competent in the makers CoP, they need to able to create things by themselves, be passionate about technology, design and making, have knowledge and expertise in the use and maintenance of tools, and be able to communicate their ideas to people from different backgrounds in the community. Students noted that a competent maker is someone who is actively trying to help people be makers and who is a curious problemsolver with good observational and teamwork skills.

\subsection{Identification with Engineering Making}

5.3.1. Imagination. The participants in the study identified engineering practice as being about problemsolving and design. They all said their knowledge of engineering practice is limited to what they have learned in school, what they have heard from family members and what they have heard from friends who are practicing engineers. However, they all agreed that they imagine the engineer they want to be as someone who is going to use their skills to contribute to the betterment of society.

"I think when it comes to me, and what kind of an engineer I am going to be in the future, I just want to be one that makes a difference in terms of how I use my problem-solving skills. I want to be a guy who makes a business and has the money to do whatever is right." - a first-year male software engineering student

"I have a pretty clear image of myself as an engineer. So, for example, I can say my image of myself is to be one of the head [people] in my country for electricity. So, I really want to give those people, like, hope that things can be built. So, for myself I'm seeing myself with my company, so I already always say that I want to have my [own] company, and then my company will provide electricity to people that need to have electricity, or if I can go further to start developing my country to become a more developed country. So, that is basically what I see myself doing as an engineer." - a third-year male electrical engineering student

5.3.2. Participation. Being a member of the makers CoP has allowed students to gain access to authentic engineering activities through the projects they do in the makerspace and to construct an image of the engineers they wish to be. This access to engineering practice has also allowed engineering students to develop and improve skills that are less emphasized in engineering school, such as teamwork, communication of engineering ideas, lifelong learning skills, innovation and creativity. The makerspace has also opened opportunities outside campus for students, as they interact with engineers who use the space on community day. These opportunities have exposed students to hands-on learning that has led them to explore the boundaries of engineering practice, such as the interaction between engineers from different disciplines, as well as codes and certification requirements and the needs of the users of their designs. An example of such exposure is the experience that one of the students who participated in our study got when he landed a summer job working in the engineering department of a long-term care hospital in Ottawa, partly thanks to experience he had gained in the makerspace; "Mu" was exposed to the biomedical product development environment when he worked with the hospital biomedical engineers and got to experience the process of product development, certification and approval. Although parts of the process were frustrating, the student was able to gain first-hand knowledge of the challenges of bringing new products to market.

"In a sense that if you make something that is useful to somebody, and make them aware that they can make something useful out of it, ... it's exactly where I want to be in the future.... So, you make something that is ethical - for example, you make something for a patient to use to solve their problem and make them more comfortable. However, the law states that they [can't use it] unless it 
passes CSA testing and all [these] extra boundaries they put on you - they limit you in a sense. I always look at law and policy in this sense and just throw them to the side; it's like $\mathrm{OK}$, but it works, and we have tried thousands of times and it works - why not just give them to a person and make their life better, because it's clear that nobody is going to pick a product that is going to benefit $1 \%$ of the population, right?! There is no company ever [that is] going to invest in that and put the money for it to be approved or to go through professional testing, so why do we strip these people down when there are people who want to help them ... and make their life more comfortable? But we say 'no' just because of policy or because the insurance company is going to pay a little bit extra money if something is burned down." - a fourthyear male computer engineering student

Challenges that members of the makers CoP faced as engineering students were managing time and their heavy engineering course load, in particular, striking a balance between courses with heavy technical demands and those that emphasize entrepreneurship and soft skills such as presentation, communication and teamwork skills.

"I think [the main challenge is] trying to balance soft and hard skills, because ... the courses are very much focused on technical skills, and I also love the business and entrepreneurship side of engineering. And sometimes it can be a little hard to balance those two because the course load is so much heavier with technical courses. But I find the courses in entrepreneurship and professional practice tend to be pushed to the side a little bit more." - a first-year female computer engineering student

On the other hand, students said the challenges they faced as makers included gathering all the information required to build a project at the beginning, continuing to have motivation for learning without being incentivized to do so through grades, making sure their projects succeeded and were done the way they wanted them to be done, dealing with the financial constraints to realizing projects, and balancing time between school work and personal projects in the makerspace.

"The main challenge I face is when I have a project and have no idea how to do it. ... I was all by myself, as the person who gave me the job saw it on the internet but didn't know how to do it. So, I was basically supposed to do it by myself, and that was one of the main challenges." - a fourth-year male electrical engineering student
"I think as a maker it would almost be the same thing, because as an engineering student the course load tends to be very high, and I tend to focus less on everything in the maker community, so I use the makerspace less because I am focusing so much on the technical courses we have, but I find that I have less time for personal projects." - a first-year female computer engineering student

5.3.3. Alignment. Students in the makers CoP noted that engineers are accountable for the usability and safety of their designs, for ensuring compliance with ethics, laws, codes and standards, for meeting public expectations of engineers and also for making the world a better place. On the other hand, they thought makers should be accountable to a culture of sharing knowledge. They emphasized the expectation in the community that its members motivate people to be makers. They also noted that the community imposes no restrictions on what users of the space can create and saw no limitation to what makers can do.

\subsection{Opinions on Engineering Education}

Students expressed their view that there is less emphasis on entrepreneurship and business classes in engineering school and that they would prefer there to be a balance between those courses and technical engineering courses. This keen interest in entrepreneurship and business courses might be a characteristic of engineering students who identify as makers only. Further research is required to understand if exposure to business training is of interest to the population of engineering students in general. They also noted a lack of a making component in engineering courses, as they were required to create prototypes only in design courses. They differentiated between lab work in engineering courses and their making activities in the makerspace: in engineering courses they are shown demonstrations of how technologies work in the real world, while in the makerspace they feel that they have no limitation to what they choose to create. In addition, there was a clear desire for more experiential learning in engineering school.

Students said that had the makerspace not existed, they would have been disappointed because they wouldn't have had as much access to hands-on engineering activities and they wouldn't have found their makers community. Overall, students said they were satisfied with their experience at the faculty and that the makerspace was a major part of their campus life. 
"In my first year, I [was] not sure if I wanted to be an engineer anymore. I was taught a lot of math and a lot of things that ... weren't necessary for me to learn, and I wasn't liking the process then; and I went under the assumption that engineering is going to be a boring theoretical line, while I [had] tried to avoid that when I applied to engineering. I didn't want to go into science because of that." — a third-year male electrical engineering student

\section{DISCUSSION}

We found that membership or entry to the makers CoP was facilitated through other programs hosted in the makerspace. Members of this community of practice were from different engineering disciplines and from faculties other than engineering. We also noticed that ensuring the consistency of workshops, courses and volunteering opportunities for students was vital to ensuring accessibility to the makers CoP and its growth. The integration of making components into engineering courses played a vital role in ensuring that the makers CoP consistently has newcomers to the community. It also exposed engineering students to the benefits of projectbased learning, rapid prototyping and visualizing their designs.

Students who start as newcomers or volunteers or who participate in training and gain more knowledge as they spend more time in the makerspace grow to become mentors to other students; hence, we found that the growth of this makers $\mathrm{CoP}$ was central to the peer learning environment in the makerspace. In addition, encouraging newcomers and ensuring that there is equal access to opportunities for the entire student population was also important to the growth of this $\mathrm{CoP}$, as students who were interviewed in this study were all newcomers who became leaders in this CoP in the average span of two years of their participation.

We also found that engineering students who were members of this makers CoP developed a strong sense of their engineering identity by constructing an image of themselves as future engineers. This was facilitated by engaging in design and engineering activities in the makerspace via personal projects at first and then through courses hosted in the makerspace or through interactions with engineers and other professionals who visited the makerspace on community day. It was also facilitated by gaining access to niche technologies and finding a space where they could explore their creativity and interests while practicing engineering skills they gained at school at the same time.

Members of this makers CoP recognized the landscape of engineering practice and the real interactions between different professional communities of practice in engineering. In addition, they had a clear understanding of their responsibility as engineers, designers and makers to the users of their designs as well as the challenges of meeting laws and standards. It was also clear that students saw their role as makers as being innovators and product developers. Moreover, the impact of students' membership in this CoP clearly boosted their confidence in their skills, their profession and their future role of contributing to the betterment of society. We also noticed that boundary negotiations between different practices and industries were clear in the students' descriptions of projects they had been involved in, whether in describing frustration with the lengthy process required for getting a project approved by a client, or the importance of other occupations and practices in implementing engineering solutions. We think this level of understanding of the boundary of engineering practice and where it interacts with other professions was attained through authentic activity experienced through this CoP.

The definition of competency in this makers CoP was not limited to knowledge about tools but was expanded to skills such as creativity, passion about design and communication of ideas to engineers and individuals, as well as the ability to mentor and motivate newcomers to the community to become makers. Table 2 outlines the characteristics of maker and engineer identity that students highlighted. Students in the makers CoP defined engineers as makers and thought that everyone can be a maker.

Table 2: Engineer and Maker Characteristics.

\begin{tabular}{|l|l|}
\hline Identity & Characteristics \\
\hline Engineer & $\begin{array}{l}\text { Problem-solvers } \\
\text { Designers }\end{array}$ \\
\hline Maker & $\begin{array}{l}\text { Curious } \\
\text { Help others } \\
\text { Lifelong learners } \\
\text { Problem-solvers } \\
\text { Observers of their surroundings }\end{array}$ \\
\hline
\end{tabular}

Although students were satisfied with their experience at the Faculty of Engineering so far, we note that none of the students had a clear picture of what to expect when they first walked in. They all noted frustration with the lack of experiential learning opportunities in traditional engineering courses, as well as frustration that the labs and projects offered in a classroom setting were different from what they do in the makerspace. However, they all expressed the view that the makerspace has been central 
to their experience at the faculty and that it has compensated for the lack of a making component in the faculty.

\section{CONCLUSION}

Our research indicates that by fostering a makers CoP, the makerspace program in the University of Ottawa has helped students develop an image of the role of an engineer as someone who provides value to society through problem-solving and designing for usability. This emphasis on the development of an image is in line with recommendation from Stevens et al. [21] for engineering programs to emphasize the development of an engineering identity during the early years of undergraduate engineering education to ensure that students develop nascent identification with engineering that goes beyond "personal material gain" [21]. All the student members of this makers CoP who were interviewed for this study related to an image of future engineers who contribute their engineering knowledge to society and help to improve people's lives by solving problems.

Being a member of the makers CoP has affected students by engaging them in the faculty, by providing an environment that fosters peer and hands-on learning opportunities and access to a social space, by increasing their confidence in what they can do, and by allowing them to experience authentic engineering practice. It has also affected their experiences at the university by connecting them with other members from different walks of life.

\section{Acknowledgements}

This work is supported by the Natural Sciences and Engineering Research Council of Canada (Chair in Entrepreneurial Engineering Design).

\section{References}

[1] National Academy of Engineering and National Research Council, Engineering in K-12 Education: Understanding The Status And Improving The Prospects. Washington, D.C.: National Academies Press, 2009.

[2] M. Prince, "Does Active Learning Work? A Review of the Research," J. Eng. Educ., vol. 93, no. 3, pp. 223-231, Jul. 2004.

[3] L. Martin, "The Promise of the Maker Movement for Education," J. Pre-College Eng. Educ. Res., vol. 5, no. 1, Apr. 2015.

[4] T. Kalil, "Have Fun-Learn Something, Do
Something, Make Something," pp. 30-34, Mar. 2013.

[5] K. Sheridan, E. R. Halverson, B. Litts, L. Brahms, L. Jacobs-Priebe, and T. Owens, "Learning in the Making: A Comparative Case Study of Three Makerspaces," Harv. Educ. Rev., vol. 84, no. 4, pp. 505-531, Dec. 2014.

[6] A. M. Thomas and D. Besser, "The Maker Movement and Engineering," Bridg., vol. Volume 47, no. 3, pp. 32-36, 2017.

[7] D. C. Holland, Identity and agency in cultural worlds. Harvard University Press, 1998.

[8] K. Deaux, "Reconstructing Social Identity," Personal. Soc. Psychol. Bull., vol. 19, no. 1, pp. 4-12, Feb. 1993.

[9] H. Tajfel, Differentiation between social groups : studies in the social psychology of intergroup relations. Published in cooperation with European Association of Experimental Social Psychology by Academic Press, 1978.

[10] D. Abrams, "Processes of social identification," in Social psychology of identity and the self concept, G. M. Breakwell, Ed. 1992, p. 271.

[11] M. Hogg and D. Abrams, "Towards a singleprocess uncertainty-reduction model of social motivation in groups.," in Group motivation: Social psychological perspectives, M. A. Hogg \& D. Abrams, Ed. 1993, pp. 173-190.

[12] D. Abrams and M. A. Hogg, "Collective Identity: Group Membership and Self-Conception," in Blackwell Handbook of Social Psychology: Group Processes, Oxford, UK: Blackwell Publishers Ltd, 2008, pp. 425-460.

[13] K. Deaux, A. Reid, K. Mizrahi, and D. Cotting, "Connecting the person to the Social: The functions of social identification," in The Psychology of the Social Self, T. R. Tyler, R. Kramer, Moreland, and O. P. John, Eds. Mahwah, N.J. : Lawrence Erlbaum Associates, Publishers, 1999, pp. 91-112.

[14] J. P. Gee, "Identity as an Analytic Lens for Research in Education," in Review of Research in Education, vol. 25, no. 1, 2007, pp. 99-125.

[15] E. Wenger, R. McDermott, and W. Snyder, Cultivating communities of practice: A guide to managing knowledge. Harvard Business Press, 2002.

[16] K. Handley, A. Sturdy, R. Fincham, and T. Clark, "Within and beyond communities of practice: Making sense of learning through participation, identity and practice," J. Manag. Stud., vol. 43, no. 3, pp. 641-653, 2006.

[17] J. Lave and E. Wenger, Situated learning: legitimate peripheral participation. 1991, vol. 29, no. 2. 1991. 
[18] J. Lave, "Situating learning in communities of practice," Perspect. Soc. Shar., 1991.

[19] E. Wenger and B. Wenger-Trayner, "Learning in landscapes of practice: A framework," in Learning in landscapes of practice: boundaries, identity, and knowledgeability in practice-based learning, Etienne Wenger-Trayner, Mark FentonO'Creevy, Steven Hutchinson, Chris Kubiak, and and Beverly Wenger-Trayner, Eds. Taylor and Francis, 2014, pp. 11-30.
[20] G. N. Svarovsky, D. M. B. Bequette, and L. Causey, "Making Connections: Challenging the Perceived Homogeneity of Making: American Society for Engineering Education," in American Society of Engineering Education, 2017.

[21] R. Stevens, K. O'Connor, L. Garrison, A. Jocuns, and D. M. Amos, "Becoming an Engineer: Toward a Three Dimensional View of Engineering Learning," J. Eng. Educ., vol. 97, no. 3 , pp. 355-368, Jul. 2008. 